\title{
MISE EN ABYME Y AUTOCONCIENCIA NARRATIVA en Basura de Héctor Abad FACIOLINCE
}

\author{
MISE EN ABYME AND NARRATIVE SELF-AWARENESS \\ IN BASURA BY HÉCTOR ABAD FACIOLINCE
}

Ana Marta Salcedo ${ }^{1}$

Artículo derivado del curso Prácticas Hermenéuticas de la Universidad Eafit.

Cómo citar este artículo: Salcedo, A. M. (2019). Mise en abyme y autoconciencia narrativa en Basura de Héctor Abad Faciolince. Estudios de Literatura Colombiana 45, pp. 123-138. DOI: https:// doi.org/10.17533/udea.elc.n45a 07

anasalcedo2003@yahoo.com

Ministerio de Educación Nacional, Colombia

Recibido: 14.02 .2019

Aprobado: 12.04.2019

Copyright: $\odot 2019$ Estudios de Literatura Colombiana. Este es un artículo de acceso abierto distribuido bajo los términos de la Licencia Creative Commons Atribución No comercial - Compartir igual 4.0 Internacional

Resumen: el estudio propuesto busca examinar, en particular, los procedimientos metafictivos de mise en abyme y autoconciencia narrativa que operan en la obra Basura (2000), los cuales develan un proceso autoconsciente de escritura exteriorizado a través de comentarios especulares que confirman la presencia del "espejo" entre los textos intercalados y el relato-marco que los contiene. Para este fin, se apoya en los postulados teóricos de Lucien Dällenbach y Jaime Rodríguez, postulados que sirven de puente para ilustrar de qué manera la variedad de juegos intertextuales que ofrece esta novela configura una visión especular del autor-personaje en su proceso de creación y ayudan a reflexionar sobre el quehacer artístico. Asimismo, identificar cómo la acción es refigurada tanto por el narradorpersonaje como por el lector extradiegético en su paso por las tres mímesis propuestas por Paul Ricœur.

Palabras clave: mise en abyme; autoconciencia narrativa; espejo; lector; Héctor Abad Faciolince.

\begin{abstract}
This article has as main objective to examine, in particular, the metafictive procedures of mise en abyme and narrative self-awareness that operate in the novel Basura (2000), which reveals a self-conscious writing process exteriorized through specular comments that confirm the presence of the "mirror" between the interleaved texts and the narrative framework containing them. For that purpose, this article is founded on Lucien Dällenbach and Jaime Rodriguez theoretical principles, which play as a bridge to illustrate how the variety of intertextual games offered in the novel, shape a specular vision of the author-character in its creation process and they help to reflect on artistic work. Likewise, to identify how the action is re-figurated both by the narrator-character and by the extradiegetic reader in its passage through the three mimesis proposed by Paul Ricœur.
\end{abstract}

Keywords: mise en abyme; narrative self-awareness; mirror; reader; Hector Abad Faciolince. 


\section{Introducción}

En la novela Basura (2000), Héctor Abad Faciolince describe a dos personajes-autores cuya prosa devela una forma particular de pensarse a sí mismos, presentando a través de su creación una serie de comentarios reflexivos que reflejan un proceso de escritura autoconsciente. Las acciones se presentan per se, en una serie de imbricaciones que se fusionan de manera rizomática provocando insospechadas conexiones y desconexiones.

Se da lugar a la narración en un edificio ubicado en el barrio Laureles de Medellín, donde vive un anciano escritor cuyo seudónimo es Bernardo Davanzati, autor de dos libros: Diario de un impostor y Adiós a la juventud. Aunque continúa escribiendo, tira sus borradores porque se avergüenza de las limitaciones de su prosa y no quiere ser leído por nadie. Sin embargo, un vecino suyo, sin pretenderlo, se topa con sus escritos entre la basura y comienza a leerlo hasta el punto de obsesionarse con la información de carácter biográfico que cree desvelar en su escritura. Por esta razón, emprende la misión de rescatar, en medio de los desperdicios, las páginas desgranadas de alguien que sufre la amargura de su existencia.

Este vecino, periodista además, motivado por la pasión hacia una posible obra literaria que cree avizorar en los escritos de Davanzati, ${ }^{1}$ se convierte, gracias al recurso del manuscrito encontrado, artificio utilizado por Abad Faciolince para darle la autoría de la obra, en el narrador de una biografía compuesta por residuos escriturales: mezclas de recuerdos y hechos reales ficcionalizados en los que Davanzati se oculta tras una voz que monologa acerca de su posición frente a la literatura y su desprecio como escritor de ficciones.

Así, puede señalarse en el plano de la historia, a un narrador, el periodista, quien se presenta en la posición heterodiegética de informador anónimo, describiendo los hechos en tercera persona de una forma ulterior. Sin embargo, él habla y opina en primera persona en su manuscrito, convirtiéndose así en un narrador-personaje que puede reflexionar sobre lo que va ocurriendo en la diégesis y se prefigura como testigo en la historia que termina autogenerando. ${ }^{2}$

\footnotetext{
$\overline{1} \quad$ Pese a que este periodista reconoce un marcado experimentalismo en la escritura de su vecino, caracterizada por reiterados saltos temporales y complejidad en la sintaxis, advierte la posibilidad de reconstruir una memoria narrada tal como la advirtió en Martín Morán, personaje de Diario de un impostor, novela que, a criterio suyo, debería volver a imprimirse.

2 Con el fin de no presentar ambigüedad en el señalamiento de los personajes analizados (Davanzati y el periodista), se llamará al primero autor-personaje y al segundo narradorpersonaje, teniendo en cuenta que ambos son autores y personajes dentro de la diégesis, y lectores fuera de esta.
} 
Gracias a su lectura consagrada y a la ayuda de una antigua amante de Davanzati, Anapaola, es posible conocer el "dato escondido" de la biografía que se propone reconstruir. Este recurso literario bautizado por Vargas Llosa (1999) consiste en silencios significativos, datos escamoteados por un astuto narrador que se las arregla para que las informaciones que calla sean, sin embargo, locuaces y azucen la imaginación del lector, de modo que tenga que llenar aquellos blancos de la historia con hipótesis y conjeturas de su propia cosecha (p. 127).

La posibilidad de jugar con espacio y tiempo le permite al periodista adentrase en la mentalidad del otro y estructurar el hilo de la trama desde una dimensión que proviene de una realidad ajena. De igual modo, la experiencia le posibilita efectuar un proceso de escritura autoconsciente donde reflexiona sobre su quehacer estético y establece relaciones a nivel intertextual entre los relatos que recoge y el relato-marco en el que los intercala.

Por lo tanto, a efectos de indagar el aspecto metaficcional en esta obra, el estudio propuesto apunta a un plano de doble referencia: por un lado, analiza el proceso de mise en abyme estudiado por Dällenbach, que se presenta en algunos relatos intercalados en el texto y que permiten, a través de diversos artificios narrativos, reconocer el reflejo con el relatomarco en el que están interpolados. Por otro lado, hace un acercamiento al concepto de autoconciencia narrativa (puesta en abismo para razonar sobre la ficción misma) estudiado por Jaime Rodríguez, el cual permite identificar la posición de los personajes-autores con respecto a su trabajo estético.

Finalmente, se presenta una reflexión en torno a la lectura como eje central de la configuración textual y, por consiguiente, al papel del lector como sujeto dialógico, quien en su recorrido por los estadios de las tres mímesis participa de la estrategia de persuasión del narrador, tal como lo plantea Paul Ricœur en su obra Tiempo y Narración (1995). En esta línea de sentido, el análisis permitirá entender cómo el juego textual que ofrece Basura ayuda a la reflexión de la lectura como interpretación del mundo configurado tanto del autor-personaje como del narrador-personaje.

\section{Mise en abyme}

Como se sabe, el relato-marco que el narrador-personaje presenta al lector es una aproximación narrativa a la biografía de su vecino Davanzati. Esta, la biografía, es construida a partir de datos develados como "reflejo" en pedazos de historias secundarias que son incluidas y comentadas al 
interior del metarrelato que escribe. En connivencia, algunos de los relatos son insertados en forma espiral, lo que da presencia a un juego especular con la biografía que los contiene, el "relato-madre".

A este respecto, Jean Ricardou, en Problémes du noveau roman (1967), haciendo notar la analogía entre la inclusión heráldica de un escudo dentro de otro y el reflejo como consecuencia, denomina este proceso mise en abyme: "Fenómeno de la inclusión, dentro de una obra pictórica o literaria 'reflejo' de la escena pintada o relatada" (p. 97). Seguidamente, Lucien Dälenbach (1991), atendiendo a lo planteado por Ricardou, señala que este recurso corresponde a "todo enclave que guarde relación de similitud con la obra que lo que la contiene" (p. 15).

Teniendo en cuenta lo señalado, el boceto de la novela Rebus que Davanzati decide iniciar, brota como un texto dentro del texto, y pese a su posición subordinada en el discurso prefigura un espejo de lo que habrá de ocurrir en el relato-marco. Se construye, entonces, un tipo de puesta en abismo de duplicación apriorística definida por Dällenbach (1991) como "un fragmento en que se supone que está incluido la obra que lo incluye" (p. 48). Por tanto, en este relato se reflecta especularmente la psicología del autor-personaje y lo que actualmente está viviendo, aspectos que rastrea el narrador-personaje en las diversas lecturas que hace.

Este esbozo de novela es narrado en tercera persona. El protagonista es Serafín Quevedo, un escritor de 33 años, cojo (a causa de una vacuna antipolio creada por su padre), quien funda con sus amigos la revista Rebus. En el plano de la historia se observa una abundancia de interpolaciones, rupturas temporales, analepsis y prolepsis para detallar la vida de los personajes y el proceso de creación de la revista. Serafín es descrito por la voz narradora como un ser de carácter débil y una personalidad variable:

Parecía estar a toda hora en el borde entre la cordura y la demencia [...] A ratos parecía el hombre más feliz del mundo, ponía cara de ángel y era tan simpático que podía lograr que tres mujeres al tiempo se enamoraran de él a pesar de su pie de plastilina. Pero también era capaz, pocas horas después, de que las tres mujeres lo odiaran sin atenuantes, porque lograba ser agrio como el óxido (Abad Faciolince, 2000, p. 64).

La circunstancia expuesta es utilizada como pretexto por su esposa Débora para abandonarlo, tras enamorarse del clarinetista de la orquesta filarmónica. En este punto, la novela es interrumpida con una sucesión de 
párrafos que develan a Serafín como una proyección del estado interior del escritor Davanzati:

\begin{abstract}
¿Pero qué hago? Débora no es Rebeca, Serafín no soy yo [...] estoy obnubilado por los defectos del cuerpo, el peor defecto es la edad, estoy muy viejo, odio estar viejo, morirme, Ahh, esto está roto, no soy capaz de inventar nada y menos de recordar. No puedo escribir de Débora con él porque entonces la ira, la tristeza, la desesperación se me agolpan en la cabeza, en los dedos, todo ese pasado fangoso y mefítico vuelve a surgir, vuelvo a verla a ella, a Rebeca con él, y vuelvo a verme a mí vengándome de mí mismo. Yo, Serafín, el ángel que se convierte en diablo. Yo, el culpable. Otra vez el deseo de hacer lo peor, de destruir mi vida (Abad Faciolince, 2000, pp. 92-93).
\end{abstract}

Este artificio narrativo erige, indudablemente, a Serafín en el alter ego de Davanzati, y a su vez el personaje creado, Débora, constituye una imagen de Rebeca, su esposa - dato que el narrador-personaje y el lector/ espectador solo conocerán hasta el final-. De acuerdo con esto, Abad Faciolince recurre a la técnica de reduplicación interna para crear su novela, pues presenta a un autor-personaje ambivalente, quien yuxtapone la realidad y la ficción en su escritura creando una figura autoral que lo represente. Serafín le permite expresar su mundo emocional y su vida misma; al contar su aventura es a la vez autor y personaje. Davanzati, por ende, trata de novelar poniendo de revés su verdad histórica y la manipula para adecuarla a los requerimientos de su ficción. Este desdoblamiento fue intuido por el narrador-personaje desde el inicio de su lectura:

Era el boceto inacabado de algo que tal vez nunca llegaría a ser. Si tengo el descaro
de transcribirla es porque creo que en ella hay ciertas claves necesarias para
entender la vida, el fracaso, el derrumbe de la vida de Davanzati, y también su
adicción a las palabras como único contacto con la realidad como muleta para
seguir en pie (p. 76 ).

Como corolario, esta composición que el autor-personaje considera basura constituye un punto de arranque para que el narrador-personaje, a pesar de no tener certeza de que los datos que tiene hasta el momento sean verdaderos, otee la dimensión psicológica de este fabulador de ficciones. Derivado de esto, el análisis en este punto se enfocará en un juego intertextual de circularidad mise en abyme que configura un espejo entre dos cartas que aparecen como relatos intercalados por el narradorpersonaje y el relato Rebus antes mencionado. 
En la primera, el remitente tiene el nombre de Bernardo y el destinatario es una mujer llamada Rebeca. Esta carta es relatada en primera persona, donde la voz narradora refleja a través de comentarios especulares rasgos parecidos a los de Serafín, personaje principal de Rebus, tal como lo indica el narrador-personaje dirigiéndose al lector: "En esa noveleta abortada que ya han leído, Rebus, hay un músico que se roba a una mujer amada y esa mujer amada tiene una hija. Hay un indicio de lo mismo, el robo del músico en la carta a Rebeca" (Abad Faciolince, 2000, p. 105). Quizás por esta razón (presunción del narrador-personaje), Davanzati pusiera música clásica a tan alto volumen.

Congruente con esto, la carta indica una relación especular con Rebus ya que remite a idénticas zonas temáticas: fracaso como escritor, ruptura del matrimonio, estado emocional inestable y de soledad y, por ende, una duplicación simple con el relato-madre, pues aunque es solo un fragmento de la obra, refleja su totalidad: la vida de Davanzati y su percepción estética. Así, este relato le proporciona al narrador-personaje nuevos indicios para revelar el enigma sobre la identidad y el pasado de Davanzati: razones del fracaso matrimonial, existencia de una hija y posible nieta, muerte del violinista Federico (esposo de Rebeca), datos que este escritor tomará como una confesión de Davanzati.

Ahora bien, la segunda carta devela un carácter totalmente autobiográfico. La voz narradora declara su completo silencio y su felicidad por haberse retirado del oficio de escritor, y señala que: "Hay que quedarse, entonces, cada vez más solo y más solo [...]. Encerrarse, meterse definitivamente dentro del cascarón para que dejen de zumbar los abejorros" (p. 111). Además, arroja datos como lugar de residencia, vecinos, posición frente a la literatura; datos idénticos a los que el narradorpersonaje está reconstruyendo en la biografía de Davanzati.

La situación expuesta prefigura un juego intertextual con los enclaves ya mencionados, pues aquí la voz narradora espera una respuesta de Rebeca, personaje mencionado en la primera carta, y siente la misma soledad y desasosiego que la voz monologada en esta, lo que hace pensar al narrador-personaje que estos dos relatos están íntimamente relacionados con lo que sucede en Rebus y, por ende, en la vida real de Davanzati.

En esta misma línea, el relato titulado El ensimismado, reconocido por el mismo Davanzati como su memoria, posibilita también la mise en abyme, pues al hacer alusión a los personajes: esposa, hija, amante y amigos 
"sombras del pasado", acerca al narrador-personaje hacia el reconocimiento de las pistas y le permite ordenarlas de tal modo que alternen con el relato en el que se encastran, advirtiendo el espejo que presenta este enclave con la vida real de Davanzati.

Así las cosas, la mise en abyme se insinúa con mayor fuerza cuando el narrador-personaje logra encontrar al comunista José, uno de los amigos de Davanzati mencionado en el relato El ensimismado, quien en una ráfaga de lucidez le cuenta de qué modo el escritor tuvo el gran descenso en su vida a partir del fracaso con su libro y matrimonio. Al finalizar el relato, el anciano evoca a su amigo: "[...] yo lo miro todavía con más lástima: es un hombre roto, derrotado, que no fue capaz ni de escribir ni de recuperar a la mujer que amó. [...] Uno puede ser víctima de su propio carácter, sabe...” (Abad Faciolince, 2000, p. 132).

A medida que se avanza en los relatos plasmados por el narrador autodiegético, se evidencian comentarios especulares de la voz narradora utilizada por el autor-personaje, los cuales tienen en el trasfondo su fracaso como escritor de ficciones, más precisamente en su papel de novelista, lo que evidencia un repliegue de la escritura de Davanzati sobre sí mismo: "[...] un escritor mediocre, sufrido pero incapaz, meritorio por el esfuerzo pero mediocre a pesar de lo esforzado. [...] Estaba incomunicado con el mundo y enterrado vivo" (p. 135).

Con todo esto, y continuando con la misma exploración, cuando el narrador-personaje escucha la versión de Anapaola, actante mencionada también en una de las historias, logra urdir el hilván de datos deshilachados que tiene hasta el momento. Como contrapunto, llega el conocimiento de la ficha clave: la sordera de Davanzati. Esta última referencia es de vital importancia, ya que se convierte en el dato escondido que explica el ensimismamiento de Davanzati y las constantes alusiones al silencio que intercala en sus narraciones: "día a día se iba quedando sin palabras" (p. 51), "En el silencio descansa el silencio" (p. 48). El suceso aludido provoca múltiples reflexiones en el narrador-personaje, quien no entiende cómo pudo habérsele escapado "lo fundamental" que se develaba en las constantes referencias a las mutilaciones sufridas por los personajes evocados en los relatos intercalados, reflejo especular de su limitación.

Otro aspecto a considerar en este análisis es el hecho de que el narrador-personaje asuma la adicción de Davanzati a las palabras escritas como el único contacto con la realidad, y de este modo, muleta para seguir 
en pie (p. 76). Proposición que se sitúa en la versión de mise en abyme que Lucien Dällebach, siguiendo a Ricardou, denomina textual, es decir, que describe en el enunciado aspectos temáticos del relato. De este modo, señala en su teoría del Relato Especular (1991) que "los reflejos pueden serlo del enunciado, de la enunciación o del código [...] el reflejo del enunciado existe al modo de una doble alianza cuya identificación y desciframiento presuponen el conocimiento del relato y ayudan a ampliar el sentido" (Abad Faciolince, 2000, p. 59).

En este punto, resulta interesante observar cómo en los diversos relatos creados por Davanzati, los personajes viven en soledad y padecen una limitación que de alguna manera los aleja del mundo. La sordera podría, entonces, ser una imagen invertida tanto en el relato marco por medio del ensimismamiento de Davanzati como en los diversos enclaves presentados a través de historias intercaladas, con mutilaciones y limitaciones físicas de los actores etéreos que crea.

En este caso, es válido sostener que en este juego metaficcional se comprueba la presencia del motivo reflejo, ya que los enclaves analizados guardan intrínsecas relaciones con lo que Davanzati está viviendo: una lucha inútil por no morir. Así, es preciso señalar que el espejo que se reflecta en el contenido textual de los encajes emerge del nivel de la historia real que se va reconstruyendo a partir de la diversidad de relaciones y correlaciones que el narrador-personaje establece entre estos.

Dentro de este juego de representaciones que ofrece Héctor Abad Faciolince se presentan, a través de relatos intercalados, realidades superpuestas por varios planos diegéticos donde aparecen un conjunto de situaciones y acontecimientos que tienen no pocas coincidencias con la historia en las que están insertas. La novela va transcurriendo, por consiguiente, a través de mudas (de espacio y nivel de la realidad), trasladando al lector implicado, ${ }^{3}$ el periodista, en un ir y venir entre la realidad de Davanzati y las fantasías que elucubra.

Empero, el autor-personaje crea de forma mecánica otras historias que tienen una existencia independiente y que, al ser reconstruidas por el narrador-personaje, no suponen un espejo del relato-marco, aunque en ocasiones pueden facilitar un juego de asociaciones. Este recurso recibe

$\overline{3} \quad$ El lector implicado es señalado por Ricœur como un lector modelo en tanto ve la comprensión de la obra en aras de la correcta interpretación, acción encerrada en la dialéctica de "la pregunta" y "la respuesta". Por lo tanto, la aprehensión del mundo del texto se logra a través del diálogo de ambas identidades: lector y texto. 
el nombre de "caja china" 0 "muñeca rusa" y se adecua mejor para dar cuenta de otras situaciones insertadas dentro del relato-madre pero que no contienen similitud con su estructura interna, ya que pueden sugerir una reduplicación simple en la que confluyen algunos espacios y nombres de los personajes sin que ello suponga un suceso apriorístico con la obra que las incluye, caso que sí se da de los encajes analizados.

En este sentido, estos relatos configurados como cajas chinas coadyuvan al narrador-personaje para mostrar otras situaciones que crea Davanzati de manera alternativa, y que al ser independientes de la diégesis alcanzarían correspondencia con otros artificios metaficcionales como la parodia; tal es el caso del relato "Balada del viejo pendejo" (Abad Faciolince, 2000 , p. 38) y el relato que el personaje Serafín crea en correspondencia con la narración del escritor costeño: "Yo no sé cuándo conocí el hielo pues yo nací en los tiempos de la nevera. Me acuerdo, sí, de una mañana en que mi padre me llevó a conocer a un muerto (p. 65).

Esta serie de relatos deshilvanados del relato-madre que hacen presencia en la narración sirven al narrador-personaje de excusa para dirigirse al lector heterodiegético y opinar acerca de los saltos escriturales de Davanzati, y hasta sugiere que este debió documentarse con Cervantes en lugar de Quevedo para cuidarse de esa "fiebre narrativa" de construcciones que carecen de sentido, de misterio, y se tornan complejas y ambiguas en el plano de la historia, apareciendo como mera yuxtaposición.

No obstante, la lectura de estos textos no asegura una correlación con el universo psicológico del autor-personaje, pues podrían ser más de sus ficciones, y pese a no establecer reverberaciones significativas sobre el relato marco, fijan elementos clave para que el narrador-personaje pueda también hacer crítica literaria al proceso de escritura de Davanzati.

\section{Autoconciencia narrativa}

"El problema es que nadie puede escribir después de muerto; de ahí que la solución sea vivir como si se estuviera muerto y seguir escribiendo, pero nunca publicar. Más aún: sin siquiera tener la menor intención de publicar nada" (Abad Faciolince, 2000, p. 21).

\footnotetext{
$\overline{4} \quad$ Esta técnica literaria consiste en construir una historia a la luz de aquellos objetos en los que se hallan contenidos otros de menor tamaño, en una sucesión que puede prolongarse hasta el infinito. De este modo, el relato-madre genera otros relatos derivados que en ocasiones pueden enriquecerlo o simplemente conservar un rasgo del mismo. En el análisis propuesto, estas historias son insipientes para el propósito de encontrar una reverberación con el relato-madre.
} 
Con lo hasta aquí analizado, al acercarnos a Basura (2000) nos encontramos con un trabajo de escritura en el que se evidencia un repliegue de la novela sobre sí misma. Esta forma de construcción de puesta en abismo recibe el nombre de autoconciencia narrativa. En Jaime Rodríguez (1995) es

Una intención de poner en relieve el acto procesal de la escritura [...]. El escritor asume, a través de su tiempo interior, el tema mismo de la creación escritural, de la ficcionalidad con todas sus implicaciones, y lo inserta en el mundo, en su situación (en la situación de su mundo), es decir, ejecuta una intertextualidad mediante la cual el objeto de su propia vivencia creativa se extiende (p. 46).

Con base en esta información, se puede decir que la autoconciencia narrativa en la obra estudiada se manifiesta en dos direcciones: en primer lugar, a partir de la reflexión hecha mediante el monólogo de la conciencia, es decir, de la expresión de la conciencia de Davanzati, quien es doblado por su doble (Serafín), y, en segundo lugar, por la reflexión metadiegética realizada por el narrador-personaje, el periodista.

Así, el autor-personaje, Davanzati, no dice que está narrando su propia vida, y a la vez desmerita su arte de narrar, pero mientras trata de organizar el orden ficcional de las narraciones se confunde con su realidad erigiendo un narcisismo, tal como lo plantea Linda Hutcheon cuando se refiere a los mecanismos metaficcionales, con lo que su prosa parece pertenecer a "[...] una especie de matemática reflejada que todo lo lleva y por la que todo pasa" (Dällenbach, 1991, p. 167).

Según esto, en el vaivén entre presente y pasado, realidad y ficción, Davanzati denuncia, a través de comentarios especulares realizados por las diferentes voces narradoras que elige, la propia concepción que tiene como autor: “¡POR LEER ESTA PENDEJADA, NADIE ME DARÍA NI SIQUIERA CIEN PESOS!” (Abad Faciolince, 2000, p. 42); "Los escritores que le gustaban, le gustaban infinitamente más que él mismo, a quien consideraba escritor mediocre" (p. 135). En este sentido, es menester volver a Jaime Rodríguez (1995) cuando afirma, refiriéndose a la autoconciencia narrativa, que

El sujeto que habla en el texto pone en juego sus facultades, se cuestiona a sí mismo, indaga por su identidad, por las razones de su acción, por el origen de sus sentimientos, por el lenguaje que utiliza, en fin, indaga sobre sí y sobre el mundo que lo rodea. Inclusive puede ser mímesis de la conciencia del autor y, a la vez, convertirse en estímulo de la conciencia de quien lee (p. 47). 
Desde este punto de vista, se presenta una novela desdoblada en la que Davanzati utiliza interpretaciones intratextuales por parte de los personajes creados, produciendo especularmente su constitución psicológica. Por ejemplo, en Rebus, la novela que el personaje Serafín intenta escribir, afirma: "Las riendas, quién lleva las riendas de mi existencia, quién hala los hilos de esta marioneta que soy a la merced del azar, de los encuentros casuales, de las desgracias y gracias sin aviso" (Abad Faciolince, 2000 , p.78). Seguidamente, utiliza una voz que monologa para expresar su odio hacia su producción escrita, tanto la publicada como la perdida. Además, manifiesta que la escritura le ha robado todo, lo que más quería.

Estos comentarios validan una imagen especular de Davanzati y comprueban que su universo ficcional jamás estuvo desligado de lo que estaba viviendo en el mundo real. En consonancia, Orejas (2003) afirma que la novela desdoblada es aquel relato que se autoanaliza o que incluye dentro de sí otros relatos, el texto narrativo que reflexiona sobre las relaciones entre realidad o ficción, las reiteradas intromisiones autoriales" (p. 22).

Es notable, además, que el autor-personaje reflexione sobre su escritura comunicando el hacer-hacer y el hacer-ser, términos trabajados por Rodríguez y que apoyan la propuesta de Patricia Waugh dirigida hacia un proceso de escritura consciente al interior de la obra literaria. En cuanto al narrador-personaje, se puede afirmar que este opera críticamente en el proceso de creación; es sensible, emanando diálogos con el lector y comentarios autoconscientes e intertextuales tanto de su proceso escritural como de los libros escritos por Davanzati y los desperdicios que recoge:

En esta idea de derrota, de imposible torneo mental, la novela se interrumpe definitivamente. [...] deduje que quizás él estaba dominado por el temor a terminar. [...] me producían pesar, más que pesar, angustia, sus caídas en una literatura deleznable, en una literatura que no merecía otro nombre que basura, su basura, mi querida basura. ¿Y si lo que a mí me parece peor fuera lo menos miserable? Quizás sea así, pero díganme ustedes si hay algo comestible en este bodrio (Abad Faciolince, 2000, p. 96).

En este contexto, el narrador-personaje realiza el ejercicio de encaje en su escritura a través de la asociación de cada vivencia evocada por la voz narradora de Davanzati. Por ello, el periodista a través de la lectura 
intenta interpretar ese mundo mostrando de qué modo, gracias al juego representativo creado, Davanzati logra ser guionista, actor y espectador al mismo tiempo. Bernardo y Serafín son uno y el mismo; en la triada autor/narrador/narratorio, escribe su historia y se ve escribiéndola. A este respecto, Álvaro Pineda Botero (1994) señala la metaficción como una consecuencia del proceso de autoconciencia del novelista, que induce la autorreflexividad de la obra: en el momento en que el escritor es consciente de sí mismo como tal, puede observarse en su labor creativa y surgen cuestiones en torno a su quehacer literario (p. 84).

Hasta aquí es posible plantear que el narrador-personaje da paso a la indagación literaria dentro de la literatura misma; los textos intercalados le permiten entonces establecer relaciones intertextuales con el relato-marco en aras de comprender la constitución psicológica de Davanzati. De este modo, el narrador-personaje "teje su texto", metáfora que ve la totalidad lingüística del texto como un tejido, como una red de oposiciones que se van fusionando y sugieren una continuidad de la escena representada (Segre, 1985, p. 367), destejiendo al mismo tiempo la vida de Davanzati.

En la misma línea, Patricia Waugh (1984) afirma que la novela reflexiva que se piensa a sí misma recibe el nombre de autorreferencial (p. 39). En estos términos, la metanovela que se vuelve sobre sí misma y es capaz de ostentar su condición de artificio recibe el nombre de novela autoconsciente por cuanto no fija su atención en el mundo representado, sino en el proceso de su creación mediante el acto de escribir (categoría 1) o mediante el acto de leer (categoría 2), o mediante un discurso oral, una interacción entre personajes que discuten acerca de cómo escribir la novela para incluir en ella aquel discurso (categoría 3) (Orejas, 2003, p. 59).

Como se sabe, el objetivo del narrador en esta obra se enfoca en proporcionar pistas de los acontecimientos narrados que son, al tiempo, una aproximación a la obra misma. Se acoge entonces, como resultado, una estrategia textual elíptica en la que aparece la voz de la conciencia - de la relación causa-efecto-, haciendo consciente las fluctuaciones de Davanzati y los espacios vacíos en su memoria. Por ende, este proceso configura un vehículo para transitar en la creación literaria, instaurando relaciones que se reflectan entre un texto y otro, y entablando diálogos y apelaciones con un lector plural que se ubica en el plano extradiegético, quien puede advertir la autoconciencia de la obra mediante la reflexión sobre la literatura desde el propio texto literario. 


\section{La lectura como interpretación de un mundo}

Atendiendo al círculo mimético estudiado por Paul Ricœur (1995a) que se da desde el lado de la historia narrada como un proceso inicial de prefiguración (mímesis i) en el que se afinca la construcción de la trama y cuyo recorrido tiene cumplimiento en el lector a través de los procesos de configuración (mímesis ii) y refiguración (mímesis iii), se identifica en la propuesta literaria de Basura un ejercicio que busca acercar el mundo del texto al mundo de dos lectores: narrador-personaje (sujeto del enunciado) y el lector extradiegético (ideal).

Así, pues, es posible observar dentro de la trama el desarrollo de dos mundos diferenciados, el de Davanzati y el de su lector. El primero, inmerso en las fluctuaciones de su memoria. El segundo, se siente seducido por la lectura de sus manuscritos hasta proponerse reconstruir la biografía del escritor. En consecuencia, y aludiendo a la triple mímesis, este lectornarrador afectado por la escritura autoconsciente de Davanzati se sitúa en la mímesis ii para reconstruir los relatos de su vecino y contarle al lector extradiegético no solo lo que siente y piensa Davanzati, sino lo que a sus casi setenta años este ve retrospectivamente.

Frente a esta imbricación actancial en la que convergen el mundo hipotético y el mundo fantástico dentro de la fábula, el papel del lector extradiegético es medular, ya que gracias a la estrategia de persuasión del narrador pasa a ser un lector implicado, lo que genera una respuesta a las estratagemas del autor (Ricœur, 1995b, p. 886). Referente a esto, Ricœur señala que la importancia del acto de lectura se presenta en la operación que permite la transición entre mímesis i y mímesis iii. Importancia que surge del hecho de que es a través de este acto que se puede generar la comunicación e intersección entre el horizonte de ambas entidades; "la intersección, por lo tanto, entre mundo configurado por el poema y mundo en cuyo seno la acción efectiva se despliega y despliega su temporalidad específica" (p. 866).

En este movimiento circular de la mímesis, el lector extradiegético adquiere, como se dijo, una condición de (ideal/modelo), pues, siguiendo a Orejas (2003), este tipo de construcción literaria requiere una lectura atenta, un mayor grado de participación del lector, ya que se encuentra frente a un juego intertextual en espiral entre los diversos encajes del relato-madre que requiere ser actualizado. A este respecto, Umberto Eco (1993) afirma que para organizar su estrategia textual el autor postula su destinatario, 
condición indispensable no solo de su propia capacidad comunicativa concreta, sino también de la propia potencialidad significativa. Esto es, una serie de competencias capaces de dar contenido a las expresiones que utiliza y cooperar interpretativamente de la forma prevista por él (p. 80).

El mundo de la acción es, en esta medida, el referente tanto del proceso de creación y disposición de la trama como del de la recepción. En connivencia, narrador-personaje y lector extradiegético son estrategias discursivas que participan en una serie de operaciones textuales trazadas por el autor, sujeto de la enunciación, en aras de refigurar este juego de realidades en el que el autor-personaje se ve envuelto por medio de la subjetividad perceptiva de sí mismo. La comprensión se lleva a cabo "mediante un movimiento circular continuo [...]. El círculo comienza una asociación siempre en ampliación entre las partes y el todo, en especial por que el todo no está visualizado antes que las partes y ha de visualizarse a través de estas (Iser, 2005, p. 116).

En esta línea, dicha serie de operaciones interlocutivas en las que el lector extradiegético es invitado a plantear sus propias suposiciones, así como el narrador-personaje plantea las suyas, llevan a que la lectura de ambas identidades se haga más completa, ya que estos relatos insertos se complementan y contribuyen mediante diversos artificios semánticos y pragmáticos a la creación de una imagen total del universo psicológico de Davanzati y el de la obra misma. Por ello, Eco (1993) afirma que la comprensión de la obra está supeditada a "determinadas huellas textuales" que llevan al vaivén de las interpretaciones, lo que finalmente construye el texto (p. 95).

De acuerdo con lo expuesto, en el paso de la configuración a la refiguración de la acción se presentan historias no contadas que el lector extradiegético hace suyas. Asimismo, el acto de leer conlleva a un reconocimiento de sí en el proceso de lectura y amplía los procesos de interpretación. Lector-personaje y lector extradiegético se complementan dialógicamente hacia la aprehensión de la obra, lo que confirma que solo por la mediación de la lectura, la obra literaria obtiene significación completa (Ricœur, 1995b, p. 866).

\section{Conclusión}

Según se ha observado a lo largo de este trabajo, en la novela Basura la escritura se presenta de modo especular. El autor-personaje 
inserta comentarios reflexivos en historias deshilvanadas que más tarde configurarán el relato-madre. Aquí, una parte de ellas reflectará en abyme, su percepción sobre la literatura y su propia existencia. Al igual que Davanzati, su lector, el narrador-personaje, se refiere al proceso narrativo de la novela que está escribiendo de una forma autoconsciente: se ve como personaje dentro de la diégesis, comenta la novela, se pregunta sobre la esencia del propio texto, habla con el lector extradiegético y le refiere el objetivo de su propio trabajo. Es posible reconocer entonces dos formas de mise in abyme: la primera en el nivel fábula, y la segunda desde la autoconciencia de los personajes en los niveles de la enunciación y el enunciado.

En este orden de ideas, la novela analizada permite una correlación directa tanto con el papel del lector, ejecutado por el narrador-personaje, como con el lector extradiegético (virtual ideal), quienes participan en una estrategia creada por el autor para que coexistan en procesos de configuración (dar una forma determinada) y refiguración (volver a imaginar). De esta manera, hay una búsqueda consciente de la voz narrativa para centrar sus recursos de escritura en el juego intertextual direccionado a la representación de la ficción, ofreciendo a través de la interpretación diferentes maneras de contemplar el mundo tanto del autor-personaje como del narrador-personaje.

Ahora bien, si en el contexto colombiano se mira la novela autoconsciente como mundo posible y como juego especular, Basura se erige como novela ensimismada, en la que subyacen personajes gradualmente contradictorios y mundos extraordinariamente versátiles entre la realidad y la ficción. Este tipo de novela ofrece diversas posibilidades para ampliar el concepto del relato metaficcional en términos de autorreferencialidad, ya que el lenguaje no se piensa solo como material, sino también como objeto de reflexión; la manipulación del punto de vista narrativo permite acercarse a la constitución psicológica de quien escribe. De este modo, la literatura moderna exige un nuevo tipo de lector. Se trata, pues, de un lector con la capacitad de situarse como sujeto perceptor en diferentes planos de la realidad en los que el autor crea. Como sujeto perceptor es, entonces, un sujeto que contempla e imagina, y al contemplar e imaginar, crea. 


\section{Referencias bibliográficas:}

Abad Faciolice, H. (2000). Basura. Bogotá: Punto de lectura.

Dälenbach, L. (1991). El relato especular. Madrid: Visor.

Eco, U. (1993). Lector in fabula. Barcelona: Lumen S.A.

Iser, W. (2005). Rutas de la interpretación. México: Fondo de Cultura Económica.

Orejas, F. (2003). La metaficción en la novela española contemporánea. Madrid: Arco Libros.

Pineda Botero, A. (1994). Del mito a la posmodernidad. La novela colombiana de finales del siglo Xx. Bogotá: Tercer Mundo.

Ricardou, J. (1967). Problèmes du nouveau roman. París: Éditions du Seuil, Coll.

Ricœur, P. (1995a). Tiempo y Narración I. Configuración del tiempo del relato histórico. México: Siglo xxi Editores.

Ricœur, P. (1995b). Tiempo y Narración III. Configuración del tiempo del relato histórico. México: Siglo xxi Editores.

Rodríguez, J. (1995). Autoconciencia y Posmodernidad. Metaficción en la novela colombiana. Bogotá: SI Editors, Instituto de Investigación Signos e Imágenes.

Segre, C. (1985). Principios de análisis de texto literario. Barcelona: Grijalbo Mondadori.

Vargas Llosa, M. (1999). Cartas a un joven novelista. Barcelona: Planeta.

Waugh, P. (1984). Literary self-consciousness: developments Modernism and postmodernism: the redefinition En Metafiction. The Theory and Practice of Self-Conscious Fiction (pp.20-42). New. York: Methuen. 